\title{
Type 1 Thanatophoric Dysplasia
}

National Cancer Institute

\section{Source}

National Cancer Institute. Type 1 Thanatophoric Dysplasia. NCI Thesaurus. Code C98583.

Thanatophoric dysplasia characterized by a normally shaped skull and curved femurs. It is the most common type of thanatophoric dysplasia. 